\title{
Population Policy
}

\section{through Tradable Procreation Entitlements}

D. de la Croix and A. Gosseries

Discussion Paper 2006-40

Département des Sciences Économiques

de l'Université catholique de Louvain 


\section{Population Policy through Tradable Procreation Entitlements}

\author{
David de la Croix \\ IRES \& CORE, U. cath. Louvain
}

Axel Gosseries

FNRS \& Hoover Chair, U. cath. Louvain

\section{CORE Discussion Paper 2006/81}

\footnotetext{
${ }^{1}$ David de la Croix acknowledges the financial support from the Belgian French speaking community (Grant ARC 03/08-235 "New macroeconomic approaches to the development problem") and the Belgian Federal Government (Grant PAI P5/21, "Equilibrium theory and optimization for public policy and industry regulation"). We thank Claude d'Aspremont, Michel De Vroey, Matias Eklöf, Andy Mason, Victor Rios-Rull, Philippe Van Parijs, Fabio Waltenberg, participants to conferences in Ghent, Louvainla-Neuve, Palma (ECINEQ) and SED06 for their comments on an earlier draft.

Address for correspondence: Department of Economics, Université catholique de Louvain, place Montesquieu 3, B-1348 Louvain-la-Neuve, Belgium.

E-mail: delacroix@core.ucl.ac.be, gosseries@etes.ucl.ac.be
} 


\begin{abstract}
Tradable permits are now widely used to control pollution. We investigate the implications of setting up such a system in another area - population control -, either domestically or at the global level. We first generalize the framework with both tradable procreation allowances and tradable procreation exemptions, in order to tackle both over- and under-population problems. The implications of procreation rights for income inequality and education are contrasted. We decompose the scheme's impact on redistribution into three effects, one of them, the tradability effect, entails the following: with procreation exemptions or expensive enough procreation allowances, redistribution benefits the poor. In contrast, cheap procreation allowances redistribute resources to the rich. As far as human capital is concerned, natalist policy worsens the average education level of the next generation, while population control enhances it. If procreation rights are granted to countries in proportion to existing fertility levels (grandfathering) instead of being allocated equally, population control can be made even more redistributive. Our exploratory analysis suggests that procreation entitlements offer a promising tool to control population without necessarily leading to problematic distributive impact, especially at the global level.
\end{abstract}

Keywords: Tradable permits, Population control, Pronatalist policy, Income inequality, Differential fertility, Grandfathering. JEL Classification numbers: J13, E61, O40. 


\section{Introduction}

In many countries, a gap obtains between the actual fertility rate and what is perceived as the optimal fertility rate. In some cases, fertility is deemed too high, typically out of concern for the ability of our natural environment to cope with such an anthropic pressure (climate change being a possible example) or for the capacity of the land to feed and provide enough space to so many people (a motive present a.o. in China's one-child policy, see Greenhalgh (2003)). In other cases, the actual fertility is perceived as too low. It can be due e.g. to the need to be numerous enough to support an endangered cultural identity. In some cases, it is the relative size of the various cohorts coexisting in a country that is at stake, a low fertility rate being one of the factors (together with an even more significant one: growing life expectancy) threatening the financial viability of our pension schemes and our health care systems. Other concerns about relative size of different groups within a population arise as well with respect to ethnic composition or educational level, fertility and mortality rates differing along such characteristics.

It remains an open question whether each of these grounds is legitimate, especially for those giving a significant importance to people's freedom (not) to procreate. Philosophers have actually shown that the very idea of an optimal population raises an even more fundamental challenge: as soon as we ask "optimal for whom?", it becomes clear that the answer may end up remaining unstable since the very existence of the agent with regard to whom we need to assess the benefit is itself a choice variable. ${ }^{1}$ In the present paper, we shall leave such questions aside, assuming that in a given territory at a given point in time, it can be meaningful to aim at a fertility rate different from the one expected in the absence of any state intervention. Hence, assuming that a fertility target may be defined in a meaningful manner, we shall be concerned here with the means to reach such a target.

In the presence of under-population, various measures have been proposed and adopted. For example, at least in some contexts such as post WWII, one justification for the introduction of family benefits was a pro-natalist one. Other measures include extensive parental (paid or unpaid) leave schemes, parents-friendly workplaces or the public provision of day-care. Admittedly, such measures may be promoted for reasons other than a concern for optimal fertility level, such as the need to promote gender equality, to guarantee equality among children, to encourage the fidelity of one's workers (in the specific

\footnotetext{
${ }^{1}$ The question of the optimal fertility rate is also present in the social choice literature, for two recent contributions see Michel and Wigniolle (2006) and Golosov, Jones, and Tertilt (2004).
} 
case of family benefits) or to defend the family as an institution. Yet, the pro-natalist dimension is often present among such justifications - not to mention among the effects of such policies (Demeny 1987).

In contrast, whenever over-population obtains, there is a variety of measures available to control population, ranging from information campaigns on contraception means, the liberalization of abortion or the leveling up of women's educational level, to China's onechild policy. The use of coercive anti-natalist means is problematic both because of the extent to which it reduced people's freedom (Sen 1996), but also because it threatens the ability of such means to actually reach the goals that have been set.

Now, one measure that could serve both pro-natalist and anti-natalist purposes has never been put in place so far: tradable procreation entitlements. Tradable quotas schemes have been promoted as a policy tool for several decades. They have typically been proposed and widely implemented to combat air pollution, ${ }^{2}$ overproduction (e.g. tradable milk quotas in the EU), overexploitation of natural resources (e.g. individual transferable fish quotas). It has also been proposed in other areas - while never being implemented - such as inflation control (Lerner and Colander 1980), and, more recently, asylum policy (Schuck (97) and Hathaway and Neve (1997)) or deficit control (Casella 1999). The idea is always to agree on a cap to reduce the extent of a given problem (over-production, over-inflation, pollution, excessive unemployment,), to allocate the corresponding rights to the various actors involved (states, firms and/or individuals), and to allow for tradability of such rights between the actors, in order to take into account differences in marginal reduction costs. One of the oldest of such proposals is Boulding (1964)'s idea of tradable procreation licenses to combat overpopulation.

More than forty years later, population policy is searching for tools able to deal with both over- and under-population, the latter being a more recent concern in developed countries. In this paper, we first apply the concept of tradable entitlements to population control problems. We generalize the framework with both tradable procreation allowances and tradable procreation exemptions, in order to tackle the two sides of the problem. Second, we address two central concerns regarding such a scheme, namely distributive and educational concerns. The former refers to the fact that such a scheme, especially through its tradability component, would be detrimental to the poor. The latter, refers to the interdependency of fertility and education choices. Third, we also investigate

\footnotetext{
${ }^{2}$ The 1990 Clean Air Act Amendments initiated the first large-scale use of the tradable permit approach to pollution control. The empirical analysis of Joskow, Schmalensee, and Bailey (1998) shows that the emission rights market created in 1990 had become reasonably efficient within four years.
} 
the implications of a global version of procreation entitlements, in line with comparable attempts to fight global warming (Kyoto agreement). While being inspired by earlier proposals by authors such as Boulding or Tobin, this paper should certainly not be read as an exercise in the history of economic ideas. It rather aims at exploring some of the potentialities and shortcomings of the idea of tradable procreation entitlements, with the view of proposing a new instrument of social policy to face one of today's problems.

After reviewing the literature in Section 1, we describe our benchmark model with endogenous fertility and education choice in Section 2. We introduce tradable procreation allowances granted to households in Section 3. We also generalize the system to accommodate the reverse situation, when they are tradable procreation exemptions. We look at how these rights modify the optimality conditions. Next we study the existence of equilibrium prices for these rights. We then look at whether tradability will impoverish the poor further in Section 4. Consequences in terms of education are also analyzed. In Section 5, we move from the country level to the global level. We illustrate how procreation rights could modify the fertility levels across the world. We also study the redistributive impact of an alternative allocation rule of procreation rights, granting rights in proportion to existing fertility levels (grandfathering). Section 6 concludes.

\section{Literature Review}

\section{Boulding's Proposal}

Since the middle of the 20th century there is a growing anxiety that our planet may not be able to sustain an ever increasing population. In an attempt to address this issue, Kenneth Boulding proposed (1964: 135-136):

I have only one positive suggestion to make, a proposal which now seems so far-fetched that I find it creates only amusement when I propose it. I think in all seriousness, however, that a system of marketable licenses to have children is the only one which will combine the minimum of social control necessary to the solution to this problem with a maximum of individual liberty and ethical choice. Each girl on approaching maturity would be presented with a certificate which will entitle its owner to have, say, 2.2 children, or whatever number would ensure a reproductive rate of one. The unit of these certificates 
might be the "deci-child," and accumulation of ten of these units by purchase, inheritance, or gift would permit a woman in maturity to have one legal child. We would then set up a market in these units in which the rich and the philoprogenitive would purchase them from the poor, the nuns, the maiden aunts, and so on. The men perhaps could be left out of these arrangements, as it is only the fertility of women which is strictly relevant to population control. However, it may be found socially desirable to have them in the plan, in which case all children both male and female would receive, say, eleven or twelve deci-child certificates at birth or at maturity, and a woman could then accumulate these through marriage.

This plan would have the traditional advantage of developing a long-run tendency toward equality in income, for the rich would have many children and become poor and the poor would have few children and become rich. The price of the certificate would of course reflect the general desire in a society to have children. Where the desire is very high the price would be bid up; where it was low the price would also be low. Perhaps the ideal situation would be found when the price was naturally zero, in which case those who wanted children would have them without extra cost. If the price were very high the system would probably have to be supplemented by some sort of grants to enable the deserving but impecunious to have children, while cutting off the desires of the less deserving through taxation. The sheer unfamiliarity of a scheme of this kind makes it seem absurd at the moment. The fact that it seems absurd, however, is merely a reflection of the total unwillingness of mankind to face up to what is perhaps its most serious long-run problem.

\section{Design issues}

On top of a separate and short discussion by Tobin (1970) with no reference to Boulding, Heer (1975) and Daly $(1991,1993)$ discuss Boulding's proposal. They both propose amendments or complements to the scheme's design. Such proposals essentially revolve around four issues: the need for continuous adjustments of the birth rate target, the issue

of shifting up the reproduction age through the system, the problem of early mortality and the definition of the license beneficiaries.

As to the first issue, Heer suggests that the government (and not only the individual permit users) could be allowed to buy such permits. A similar issue arises in the field of 
pollution permits, where e.g. environmental NGOs, despite not being permit users, are allowed to influence the global cap through buying permits. In the present case, Heer identifies two reasons why it may be worth allowing the government to be a permit buyer as well. On one hand, in order to deal with the problem of partial non-compliance, the government could buy on the market a number of permits corresponding with the number of unlicensed babies (Heer, 1975: 4). On the other hand, in contrast with the case of pollution permits, procreation rights are allocated for life rather than for a given period. And other factors than birth rate affect the size of a given population, most notably mortality rate and geographical mobility (immigration/emigration). As Heer writes, “(...) the original Boulding proposal guarantees only that fertility will vary narrowly around replacement level and cannot guarantee that the rate of natural increase (the crude birth rate minus the crude death rate) will be nil nor, a fortiori, can it provide for zero population growth (which would be obtainable with a zero rate of natural increase only provided there was also no net immigration from abroad)" (1975: 4). A government may thus want to adjust the amount of birth licenses to the evolution of these other factors. One could argue that allowing the government to buy permits all along would make it less necessary to adjust the amount of permits allocated to each birth cohort.

Heer focuses on a second set of amendments aimed at influencing the birth rate through raising the women's age of reproduction. Two avenues are proposed, a incentive-based one and a more standard one. As to the former, one could "allow for the possibility that individuals, until they reached age 35, could loan their license units to the government and receive interest during such time as their license units were on loan to the government" (Heer, 1975: 6). There could thus be a financial incentive to delay reproduction, which would certainly have an impact on the birth rate. The other way in which Heer proposes to influence the age of reproduction (hence indirectly the lifelong reproduction rate) consists in "stipulating that licenses to bear children be granted only at age 18 and that individuals under this age neither be allowed to purchase licenses nor to be given licenses by other persons" (Heer, 1975: 8). The two avenues (loan and minimum age) are of course not exclusive and could therefore be combined.

Child mortality is another concern for both Heer and Daly. They want to prevent the system from disadvantaging (often poorer) parents experiencing child loss. This leads to a third set of proposals. Heer proposes that "a woman losing a child before that child reached its eighteen's birthday would be given a sufficient number of license units to bear an additional child; but if a child died after its eighteenth birthday, its mother would 
receive no additional units" (1975: 8). As to Daly, his approach to the issue of child mortality implies both that licenses be granted at birth and that they be bequeathable. This is such that "if a female dies before having a child, then her certificate becomes part of her estate and is willed to someone else, for example, her parents, who either use it to have another child or sell it to someone else" (1993: 336). If on top, permits were allocated both to girls and boys (rather than to girls only), Daly's allocation at birth would offer a solution to the problem of early mortality of both girls and boys, allowing the parents to give birth to more than two children in such a case without having to buy extra permits. What is clear from this is that the answer provided to the "beneficiary definition" question has a clear impact on the ability of the scheme to address the "child mortality" challenge.

Finally, who should receive the licenses: women only, men only, both men and women? Boulding's proposal - as well as Tobin's - consists in a "ladies-only" allocation. For Heer, the possible merits of a men-only scheme include "a considerable reduction in the incidence of illegitimate births" (1975: 8) for reasons that are not entirely clear though. But other reasons are suggested as possible grounds for granting them to women only, such as the need for compensating the discriminations that women experience. In contrast, issues such as whether single-sex allocation would not be discriminatory from a gender-orientation perspective, or as to how to deal with the licenses in case of divorce once they are granted to both parents, are not examined by these authors.

\section{Distributive Impact}

Besides these design issues, other problems are considered by the three authors. The three most significant ones are: the question of the scheme's distributive impact, the problem of enforcement, and the examination of alternative means to reach the same goal.

Regarding distributive impact, Daly, as Boulding, discusses the issue. He traces possible injustices arising from the scheme back to background distributive injustices that are present anyway. Not only does he claim that existing injustices will not be worsened by the introduction of the scheme. He even argues that inequalities will be reduced, for two reasons. First, the "new marketable asset is distributed equally" (336), which does not tell us why this would reduce inequalities. Second, "as the rich have more children, their family per capita incomes are lowered; as the poor have fewer children their family per capita incomes increase. From the point of view of the children, there is something to be said for increasing the probability that they will be born richer rather than poorer" 
(1993: 336). It is not clear of course why the richer would tend to have more children as a result of the scheme. It is easier to understand why the poorer would tend to have less.

\section{Benchmark Model}

The salient feature of the benchmark economy in which we shall introduce procreation entitlements consists in fertility and education choice by households belonging to different income groups. We consider a model inspired from de la Croix and Doepke (2003). They propose a tractable framework where households are heterogeneous in terms of human capital, and low-skilled households choose to have more children than skilled ones. This theoretical set-up reflects the well-documented fact that fertility is inversely related to the education level of the mother (Kremer and Chen 2002). Differential fertility will turn to be a key element in the analysis of procreation entitlements. We first present the benchmark model without such entitlements.

The model economy is populated by overlapping generations of people who live for two periods, childhood, and adulthood. Time is discrete and runs from 0 to $\infty$. All decisions are made in the adult period of life. There are two types of agents, indexed by $i$, unskilled (group $i=A$ ) and skilled (group $i=B$ ), who differ only in their wage $w_{t}^{i}$. The size of each group is denoted $N_{t}^{i}$. Agents represent households within a country, but we will also interpret them as countries within the global economy in Section 5. Adults care about their own consumption $c_{t}^{i}$, the number of their children $n_{t}^{i}$, and the probability $\pi\left(e_{t}^{i}\right)$ that their children will become skilled. This probability depends on the education $e_{t}^{i}$ they receive. Preferences are represented by the following utility function:

$$
\ln \left[c_{t}^{i}\right]+\gamma \ln \left[n_{t}^{i} \pi\left(e_{t}^{i}\right)\right] .
$$

The parameter $\gamma>0$ is the weight attached to children in the households' objective. Notice that parents care both about child quantity $n_{t}^{i}$ and quality $\pi\left(e_{t}^{i}\right)$. As we will see below, the tradeoff between quantity and quality of children is affected by the human capital endowment of the parents. Notice also that parents do not care about their children utility, as it would be the case with dynastic altruism, but they care about their future human capital.

To attain human capital, children have to be educated. Parents freely choose the education spending per child $e_{t}^{i}$. Apart from the education expenditure, raising one child also takes 
a constant fraction $\phi \in(0,1)$ of an adult's time. This fraction of time cannot be cut down. Therefore it limits to $1 / \phi$ the number of children one family can possibly raise.

Parents provide education to their children because it raises the probability that their children will be skilled. Specifically, given education $e$, the probability $\pi^{i}(e)$ of becoming skilled is given by:

$$
\pi^{i}(e)=\tau^{i}(\theta+e)^{\eta}, \quad \eta \in(0,1) .
$$

The parameter $\theta$ measures the education level reached by a child in the absence of education spending by the parents. This education level is obtained for free and is a perfect substitute to the education provided by the parents. $\eta$ measures the elasticity of success to total educational input $\theta+e$. The parameter $\tau^{i}$ depends on the type $i$, and we assume the children of skilled parents have, ceteris paribus, a greater chance of becoming skilled themselves, i.e. $\tau^{B}>\tau^{A}$. ${ }^{3}$

The budget constraint for an adult with wage $w_{t}^{i}$ is given by:

$$
c_{t}^{i}=\left[w_{t}^{i}\left(1-\phi n_{t}^{i}\right)-n_{t}^{i} e_{t}^{i}\right]
$$

The aggregate production function for the consumption good is linear in both types of labor input. We have:

$$
Y_{t}=\omega^{A} L_{t}^{A}+\omega^{B} L_{t}^{B}
$$

The marginal product of each type of worker is constant and equal to $\omega^{A}$ and $\omega^{B}>\omega^{A}$ respectively. The total input of the groups are given by $L_{t}^{A}$ and $L_{t}^{B}$. The equilibrium condition on both labor markets $N_{t}^{i}\left(1-\phi n_{t}^{i}\right)=L_{t}^{i}$ will imply that wages are equal to marginal productivity:

$$
w_{t}^{i}=\omega^{i}
$$

Denoting the equilibrium outcome in the benchmark case with hatted variables, we end up with the following definition:

\section{Definition 1 (Equilibrium)}

Given initial population sizes $N_{0}^{A}$ and $N_{0}^{B}$, an equilibrium is a sequence of individual quantities $\left(\hat{c}_{t}^{i}, \hat{e}_{t}^{i}, \hat{n}_{t}^{i}\right)_{i=A, B . t \geq 0}$ and group sizes $\left(\hat{N}_{t}^{i}\right)_{i=A, B . t \geq 0}$ such that

\footnotetext{
${ }^{3}$ Note that, in what follows, $e$ is always bounded from above; hence we can always define the constant term $\tau^{i}$ as a function of the other parameters of the model such that the function $\pi^{i}()$ returns values in the interval $[0,1]$.
} 
- Consumption, education and fertility maximize households' utility (1) subject to the budget constraint (2);

- Group sizes evolve according to:

$$
\left[\begin{array}{c}
\hat{N}_{t+1}^{A} \\
\hat{N}_{t+1}^{B}
\end{array}\right]=\left[\begin{array}{cc}
\hat{n}_{t}^{A}\left(1-\pi^{A}\left(\hat{e}_{t}^{A}\right)\right) & \hat{n}_{t}^{B}\left(1-\pi^{B}\left(\hat{e}_{t}^{B}\right)\right) \\
\hat{n}_{t}^{A} \pi^{A}\left(\hat{e}_{t}^{A}\right) & \hat{n}_{t}^{B} \pi^{B}\left(\hat{e}_{t}^{B}\right)
\end{array}\right]\left[\begin{array}{c}
\hat{N}_{t}^{A} \\
\hat{N}_{t}^{B}
\end{array}\right]
$$

- Labor market clears, i.e.

$$
\hat{N}_{t}^{i}\left(1-\phi \hat{n}_{t}^{i}\right)=L_{t}^{i} \quad \forall i .
$$

Let us now analyze the solution to the individual maximization problem. Parents face a tradeoff between the number of children they have, and the amount of goods they spend on the education of each child. For, since productivity is fixed, having more children necessarily entails less spending per child. For educated parents, the opportunity cost of child-rearing time is higher, they will prefer to invest in the education or "quality" of a small number of children. For less educated parents, in contrast, the opportunity cost of raising children is lower, while providing education is expensive relative to their income. Parents with low income would therefore choose to have many children, but invest less in the education of each child. This notion of a quantity-quality tradeoff in the decisions on children was first introduced by Becker (1960) and is supported by empirical evidence on the cross-sectional distribution of fertility and education. Maximizing utility (1) subject to the constraint (2) leads to the following conditions. If $w>\theta /(\eta \phi)$ [interior regime],

$$
\begin{aligned}
& \hat{e}=\frac{\eta \phi w-\theta}{1-\eta}, \quad \text { and: } \\
& \hat{n}=\frac{(1-\eta) \gamma w}{(\phi w-\theta)(1+\gamma)} .
\end{aligned}
$$

otherwise,

$$
\begin{aligned}
& \hat{e}=0, \quad \text { and: } \\
& \hat{n}=\frac{\gamma}{\phi(1+\gamma)}
\end{aligned}
$$

This simple model displays the two important properties of quantity-quality tradeoff models: $\partial \hat{e} / \partial w \geq 0$, i.e. parental education spending increases in income, and $\partial \hat{n} / \partial w \leq 0$, 
i.e. fertility decreases in income. Since income in this model reflects human capital, fertility is a decreasing function of the human capital of the parents. Notice also the role of parameter $\theta$, which captures the education children receive for free (by nature or society). A higher $\theta$ pushes parents to substitute education with number of children.

Observed income inequality $\Delta^{B}$ (B for benchmark) can be measured by the difference between high skilled and low skilled income:

$$
\Delta^{B}=\omega^{B}\left(1-\phi \hat{n}^{B}\right)-\omega^{A}\left(1-\phi \hat{n}^{A}\right)
$$

This measure will be used later to assess the effect of procreation rights on income differences. In this respect it is worth emphasizing that the metric adopted in this paper is income rather than utility differences. Moreover, we focus on differences in income, as opposed to possible improvement or degradation of the income of the least well off.

The long-run properties of the model can be analyzed by defining the following population ratio:

$$
z_{t}=\frac{N_{t}^{A}}{N_{t}^{B}} .
$$

The dynamic system (3) is reduced to a first-order recurrence equation $z_{t+1}=f\left(z_{t}\right)$. In Appendix A, we show that the function $f($. $)$ satisfies: $f(0)>0, f^{\prime}(z)>0, f^{\prime \prime}(z)<0$. The last two results are guaranteed by the fact that $\tau^{B}>\tau^{A}$. The dynamics of $z_{t}$ admit a single positive steady state which is globally stable.

\section{Implementing Tradable Procreation Rights}

The government has a fertility objective of $\nu$ children per person. We do not question this objective, but only impose the reasonable condition that it should be biologically feasible, i.e.

$$
0<\nu<\frac{1}{\phi}
$$

The implementation sequence of procreation entitlements is detailed in Table 1. Let us first consider the sequence for allowances, which are designed to prevent fertility from being above the target. At her majority, each parent receives for free $^{4} \nu$ procreation

\footnotetext{
${ }^{4}$ An alternative mode of initial allocation consists in an auction. The distributive impact of such an alternative will depend to a large extent on the way in which the regulator will spend the hence collected resources.
} 
Table 1: Implementation sequence

\begin{tabular}{lll}
\hline \hline & $\begin{array}{l}\text { Allowances } \\
\left(\text { price } g_{t} \geq 0\right)\end{array}$ & $\begin{array}{l}\text { Exemptions } \\
\left(\text { price } q_{t} \geq 0\right)\end{array}$ \\
\hline At majority & receives $\nu$ rights & \\
At each birth & cedes back one right & $\begin{array}{c}\text { if number births }>\nu \\
\text { receives } 1 \text { right } \\
\text { At menopause }\end{array}$ \\
Over complete life & Procreation and exemption rights can be sold and purchased \\
\hline \hline
\end{tabular}

allowances from the Procreation Agency. We assume that each procreation allowance corresponds with the right to give birth to one child. Each time she gives birth to a child, a parent has to cede one procreation allowance back to the Procreation Agency. Procreation rights can be sold and purchased at any moment in time at a price $g_{t}$. We assume that fines are such that everyone will be deterred from violating such rules at equilibrium. ${ }^{5}$

We now consider the sequence for exemptions, which are designed to prevent fertility from being below the target. Each time a parent gives birth to a child, and as soon as observed parent's fertility $n_{t}$ becomes larger than $\nu$, she will receive free of charge from the Procreation Agency one exemption right per additional child. At the standard menopausal age, each parent having less biological children than $\nu$ has to give the Procreation Agency $\nu-n$ exemptions, which she will have purchased on the procreation exemptions market at a price $q_{t} \geq 0$. parents with more children than $\nu$ can sell on the market the un-used exemptions.

Table 1 makes visible three specific properties of a tradable entitlement scheme aimed at addressing a problem of under-provision. First, the exemptions are allocated ex post facto rather than initially. Second, in comparison with taxation, our proposal exhibits two properties. Not only is it quantity focused as opposed to price focused, but the joint operation of allowances and exemptions guarantees that the target will strictly be met;

\footnotetext{
${ }^{5}$ Such fines will have to be targeted in such ways as not to affect the children themselves. Otherwise children would be sanctioned as a matter of fact for what they are not responsible for, see Dworkin (2000).
} 
in case of tradable exemptions, we see from the table that their amount is not limited ex ante otherwise than through the biological constraint $\left(n_{t} \leq 1 / \phi\right)$; in the absence of an upper limit, reaching strictly the target cannot be guaranteed unless the system is coupled with a tradable allowances scheme, which is the case here. Third, contrary to a subsidy, the value of the exemption will fluctuate as a function of market conditions.

In our model there is no child mortality or infertility risk. In a more general set-up, these issues could addressed these issues by assuming a perfect insurance market which would cover those risks.

After inclusion of the procreation entitlements, the budget constraint for an adult becomes:

$$
c_{t}^{i}=\left[w_{t}^{i}\left(1-\phi n_{t}^{i}\right)-n_{t}^{i} e_{t}^{i}\right]+g_{t}\left(\nu-n_{t}^{i}\right)+q_{t}\left(n_{t}^{i}-\nu\right) .
$$

The variable $g_{t}$ is the price of one procreation allowance, while $q_{t}$ is the price of one procreation exemption. Since the two types of entitlements are put in operation simultaneously, only the difference $g_{t}-q_{t}$ matters. We call this difference "procreation price" and accordingly define

$$
p_{t}=g_{t}-q_{t}
$$

In equilibrium, $p_{t}$ can be positive or negative. Equilibria with positive procreation price $p_{t}$ reflect situations where fertility is discouraged, while equilibria with $p_{t}$ negative obtain in cases in which fertility is promoted. The following definition stresses that there is one additional market compared to Definition 1.

\section{Definition 2 (Equilibrium with Procreation Rights)}

Given initial population sizes $N_{0}^{A}$ and $N_{0}^{B}$, an equilibrium is a sequence of individual quantities $\left(c_{t}^{i}, e_{t}^{i}, n_{t}^{i}\right)_{i=A, B . t \geq 0}$, group sizes $\left(N_{t}^{i}\right)_{i=A, B . t \geq 0}$, and prices $\left(p_{t}\right)_{t \geq 0}$ such that

- Consumption, education and fertility maximize households' utility (1) subject to the budget constraint (10);

- Group sizes evolve according to (3).

- Labor market clears, i.e. Equation (4) holds.

- Asset market clears, i.e.

$$
\sum_{i}\left(n_{t}^{i}-\nu\right) N_{t}^{i}=0
$$




\section{Fertility and Education Choices}

In this section we drop the time index to save notation. A condition for the problem to be well defined requires the endowment of the household to be positive: $w+p \nu>0$. This condition will hold for all households if the equilibrium price satisfy:

$$
\omega^{A}+p \nu>0
$$

This condition is always satisfied when fertility is discouraged $(p>0)$. When fertility is promoted, condition (C2) imposes a lower bound on the price of procreation (i.e. an upper bound on the price of exemptions). The condition implies that a poor household wanting to have no children should be able to afford it.

As in the benchmark model, the solution to the household decision problem can either be interior, or at a corner. There is an additional difficulty compared to the problem without procreation entitlements. If fertility is strongly encouraged by a negative procreation price $p$, the biological constraint $n \leq 1 / \phi$ might be binding, i.e. some households may want to have more children than what is biologically feasible. ${ }^{6}$ In Appendix B we characterize the optimal solution. It appears that they are four different regimes depending on the procreation price and the income, which are:

- R1 Procreation price $p$ is very negative and labor income $w$ is low. The household does not work and specializes entirely into the production of children. This reproductive activity is so well paid that they can afford to provide some education to their children.

- $\mathrm{R} 2 p$ is negative and $w$ is low. The household entirely specializes into the production of children, but is too poor to provide any education.

- R3 $p$ is positive or moderately negative and $w$ is low. The household has some children, works, and doesn't provide education. This corresponds to the corner regime with no education that we already found in the model without procreation rights.

- R4 $p$ is positive or moderately negative but $w$ is high. It corresponds to the interior solution. It is obtained when the price of the procreation rights is not too low. If it

\footnotetext{
${ }^{6}$ In the benchmark model, the optimal $n$ is always below the biological maximum $1 / \phi$. Were this not to be the case, households would have no income at all.
} 
was, either households would like to offer no education at all to their children (the constraint $e \geq 0$ binds), or their economically optimal fertility would be above the biological maximum (the constraint $n \leq 1 / \phi$ binds).

Obviously, regimes R1 and R2 are anecdotic because the procreation prices for which they obtain are unrealistically negative ${ }^{7}$ but still need to be considered when studying the general equilibrium with procreation rights. From the results in Appendix B, we can establish the properties of fertility and education as a function of income and procreation prices. Let us start with the effect of income.

\section{Proposition 1 (Fertility, Education and Income)}

- For low income and low procreation price (regimes R1 and R2), small changes in income neither affect educational investment, nor influence fertility.

- For low income and high procreation price (R3), small changes in income influence fertility negatively while leaving educational investment unaffected.

- For high level of income (R4), small changes in income affect spending on education positively. They also adversely influence fertility if and only if if the price of procreation is low enough:

$$
\frac{\partial n}{\partial w}<0 \Leftrightarrow p<\frac{\theta}{1-\phi \nu} .
$$

Proof: see Appendix B.

This stresses that if $p$ is below a threshold given by $\theta /(1-\phi \nu)$, the usual result that high income parents have fewer children applies. If procreation is made sufficiently expensive through a positive price of procreation, then the usual pattern is reversed, and high income parents have more children than poor parents. For the same procreation price, the cost of children relative to total income is higher for the poor than for the rich. This feature will have important implications when it comes to assessing the distributive impact of the scheme.

Having assessed the impact of income on fertility for a given procreation price, we now move to investigating the effect of price changes on fertility rates. The following Proposition summarizes the result.

\footnotetext{
${ }^{7}$ For such prices to occur at equilibrium, we would need a radical pro-natalist target.
} 
Figure 1: Fertility as a function of income and procreation price

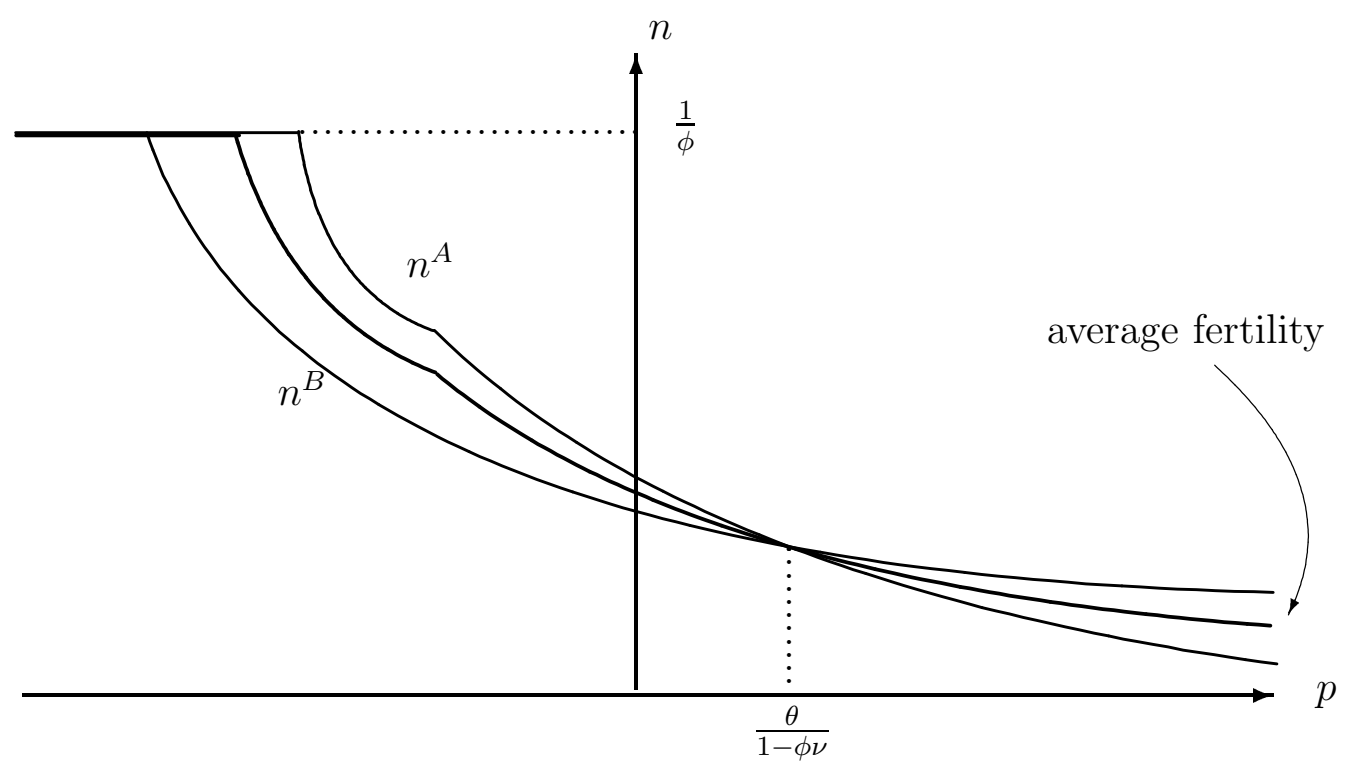

\section{Proposition 2 (Fertility and Procreation Price)}

The individual fertility rate $n$ is a decreasing function of procreation prices $p \in(-1 / \nu,+\infty[$.

Proof: see Appendix B.

Proposition 2 reflects that the demand for the quantity of children decreases with the price of children, i.e. children quantity is a non-Giffen good. Figure 1 represents an example of fertility for the two groups A and B as a function of the procreation price. Starting from the left hand side at a very negative price, the fertility rate of group A first remains constant as $p$ increases because we still remain in the zone in which procreation price is such that parents want more children than what their biological constraint allows (regimes $\mathrm{R} 1$ and R2). At a certain point the price becomes such that fertility starts to decrease (regime R3). We then observe a point at which the fertility function is non differentiable, which corresponds to the shift from a regime with no education investment (R3) to the one in which parents invest also in quality (R4). The fertility function of Group B is different as it shifts straight from the regime with maximum fertility (R1) to the interior regime (R4).

As discussed above, as long as $p$ remains below the threshold $\theta /(1-\phi \nu)$ defined in 
Proposition 1, the fertility rate of group $\mathrm{A}$ is equal to or greater than the fertility rate of group B. In case $p$ is large, however, the differential fertility is reversed.

\section{Equilibrium}

After having analyzed the effect of procreation entitlements on individual behavior, it now remains to be shown that there is procreation price such that actual average fertility will meet the demographic target set by the government.

The property outlined above that households' fertility rates are decreasing functions of the procreation price implies that average fertility is also a decreasing function of $p$. Under the condition that for the lowest possible negative price $p$ (condition (C2)) all groups are in regime $\mathrm{R} 1$, average fertility decreases from $1 / \phi$ for very low $p$ to 0 for large positive $p$. The continuity of the fertility function is then sufficient to establish the existence of an equilibrium procreation price, which implies that the target fertility rate $\nu$ is reached. The uniqueness of the equilibrium follows from the monotonicity of the fertility function.

\section{Proposition 3 (Existence and Uniqueness of Equilibrium)}

Define:

$$
\tilde{p}(w) \equiv \frac{\theta(1+\gamma)-(1+\eta \gamma) \phi w}{\gamma(1-(1-\eta) \phi \nu)+1} .
$$

If $\tilde{p}\left(\omega^{B}\right)>-1 / \nu$ the equilibrium procreation price exists and is unique.

Proof: See Appendix C.

Besides the technical constraint $\tilde{p}\left(\omega^{B}\right)>-1 / \nu$, it follows that the structure of the economy as such will not impose constraints as to the possible level of the demographic target $\nu$. This does not preclude the possibility of constraints due to other reasons, such as political feasibility or ethical reasons.

At equilibrium, our measure of income inequality $\Delta^{T}$ ( $\mathrm{T}$ for tradable) is given by:

$$
\begin{aligned}
\Delta^{T} & =\omega^{B}\left(1-\phi n^{B}\right)+p\left(\nu-n^{B}\right)-\left[\omega^{A}\left(1-\phi n^{A}\right)+p\left(\nu-n^{A}\right)\right] \\
& =\omega^{B}\left(1-\phi n^{B}\right)-\omega^{A}\left(1-\phi n^{A}\right)+p\left(n^{A}-n^{B}\right) .
\end{aligned}
$$

Hence, on top of the difference in labor income one should take into account the transfer which is generated by procreation rights $p\left(n^{A}-n^{B}\right)$. 


\section{Effects on Income Inequality and Education}

In order to assess the distributive impact resulting from the introduction of a tradable procreation scheme, it is helpful to first look at a simpler case, which is the impact of fixed quotas.

\section{Two Effects of Fixed Quotas on Income Inequality}

Examining the impact of tradable quotas schemes would not make much sense without providing a comparison of such effects with either those of a business-as-usual ${ }^{8}$ situation, or those of alternative measures aimed at reaching the same demographic target. There are two families of such alternative policy options. Either, we go for a measure that, while being quantity-oriented as well, would be of a more rigid type, i.e. fixed rather than tradable quotas. Or, we go for a variety of price-oriented measures, such as family allowances, free education,... (in case of underpopulation) or for taxation (in case of overpopulation). In the case of price-oriented methods, potential parents are totally free to chose the number of children they wish to have, under the pressure of incentives or disincentives set up by regulatory authorities. Here, we only compare tradable quotas with fixed ones, both because this is the closest realistic alternative method, as the Chinese example suggests, and because a comparison with price-oriented methods would require a much richer analytic aparatus than the one we wish to rely upon here. Let us stress as well the fact that when comparing fixed and tradable quotas, we should assume the same type of initial allocation (here: equality per head). ${ }^{9}$

Formally, fixed quotas imposes an additional constraint $n \leq \nu$ to the maximization problem studied in Section 2. If this constraint is tight for the skilled parents, i.e. if they would otherwise have more children, it will also be tight a fortiori for the unskilled. Hence, the constraint $n \leq \nu$ is tight for both groups if and only if

$$
\nu \leq \frac{(1-\eta) \gamma \omega^{B}}{\left(\phi \omega^{B}-\theta\right)(1+\gamma)}=\hat{n}^{B},
$$

The reverse situation where the government imposes a minimum fertility level can also

\footnotetext{
${ }^{8}$ Benchmark and business-as-usual are used indifferently for the purpose of this paper.

${ }^{9}$ Notice that, in Chinese one child policy, the fixed quotas are not uniformly distributed: two children are allowed for in the countryside, only one in cities. This illustrates that the uniform allocation is not the only possible option, and that allocations of quotas on the basis of other factors, such as existing fertility levels, are also possible. This point is further developed in Section 5.
} 
be analyzed. In that case, the constraint is written $n \geq \nu$. It will be tight for the poor and even more so for the rich if and only if

$$
\nu \geq \frac{(1-\eta) \gamma \omega^{A}}{\left(\phi \omega^{A}-\theta\right)(1+\gamma)}=\hat{n}^{A}
$$

Hereinafter we only envisage the former case, dealing with over-population, unless specified otherwise. The results we obtain apply mutatis mutandis to the policy dealing with under-population.

Assuming tight constraints, the solution to the maximization problem is:

If $w>\theta /(\gamma \eta(1 / \nu-\phi))$ [interior regime],

$$
e=\frac{\gamma \eta w(1 / \nu-\phi)-\theta}{1+\gamma \eta}
$$

Otherwise

$$
e=0 \text {. }
$$

In the interior regime, we have $\partial e / \partial \nu<0$. This confirms that as parents react to the quantitative constraint by having less children, they will be able to afford to spend more on each of their children.

As to income inequality, the difference between high skilled and low skilled income, $\Delta^{F}$ ( $F$ for fixed), is given by:

$$
\Delta^{F}=\omega^{B}(1-\phi \nu)-\omega^{A}(1-\phi \nu) .
$$

Comparing with Equation (12) of the tradable rights case, transfers do not obtain in this case as a result of population policy.

We compute the change in income difference resulting from the introduction of fixed quotas:

$$
\frac{\Delta^{F}-\Delta^{B}}{\phi}=\underbrace{(\hat{n}-\nu)\left(\omega^{B}-\omega^{A}\right)}_{\text {differential productivity effect }>0}+\underbrace{\omega^{B}\left(\hat{n}^{B}-\hat{n}\right)-\omega^{A}\left(\hat{n}^{A}-\hat{n}\right)}_{\text {differential fertility effect }<0}
$$

where $\hat{n}=\left(\hat{n}^{A} \hat{N}^{A}+\hat{n}^{B} \hat{N}^{B}\right) /\left(\hat{N}^{A}+\hat{N}^{B}\right)$ is average fertility in the benchmark case. The first effect, labeled "differential productivity effect" can be understood as follows. Let us envisage a hypothetical business-as-usual situation in which high-income and low-income 
people have the same fertility level $\hat{n}$. Assume that this level is higher than the one required by our demographic target $\nu$. With the introduction of non-tradable quotas the extent to which the rich will procreate less than the poor is identical. Both the skilled and the unskilled will increase their income as a result of the time made available by such lower fertility. However, since the hourly wage (and underlying it, the productivity) of the high-income is higher than the one of the low-income people, the income of the rich will increase relatively more than the one of the poor. In short, the introduction of fixed quotas to fight overpopulation in a world in which the fertility rate does not vary with the level of income, will make the poor-income relatively poorer than the high-income.

The second effect, labeled "differential fertility effect" relaxes the assumption regarding the absence of initial fertility differential (and it is equal to zero if $\hat{n}^{B}=\hat{n}^{A}$ ). In the benchmark situation low-income people tend to have more children than high-income people. Here, a second type of effect can be singled out, of a redistributive rather than of an anti-distributive nature. It can be explained as follows. If the fixed quotas scheme requires the same fertility level from the poor and the rich, the poor will have to reduce her fertility level much more than the rich. As a result, she will also increase her working time more than the rich. This effect will reduce income inequality between the rich and the poor, when compared with the income differential in the business-as-usual situation. The sign of the total effect of introducing fixed quotas on income difference depends on which of the two effects dominates. One parameter affecting the relative weight of the two effects is the elasticity of educational outcomes over investment in education, represented by $\eta$. Indeed, computing the extreme hypothetical fertility rates of households with zero income and infinite income leads to:

$$
\begin{aligned}
& n_{\max }=\lim _{w \rightarrow 0} \hat{n}=\frac{\gamma}{\phi(1+\gamma)} \\
& n_{\text {min }}=\lim _{w \rightarrow \infty} \hat{n}=\frac{\gamma(1-\eta)}{\phi(1+\gamma)}
\end{aligned}
$$

The maximum differential fertility is therefore:

$$
\frac{n_{\max }}{n_{\min }}=\frac{1}{1-\eta}
$$

If this elasticity $\eta$ is large, the fertility differential will tend to be large as well, to such an extent that the "differential fertility effect" may actually dominate the differential productivity effect. The reason underlying this connection between outcome-investment 
elasticity and fertility differential is the following. The poor is equally concerned about education as the rich. However, for the poor, the cost of investing in education as well as the opportunity cost of having children is lower than for the rich. A higher outcome investment elasticity will not affect the poor much, but will definitely push the rich the substitute quality to quantity even more. Hence, the differential fertility is larger when $\eta$ is large.

\section{Effect of Tradability on Income Inequality}

We now replace fixed quotas with tradable quotas. In order to identify the difference it makes, we compute the change in income gap between the benchmark and the model with tradeable rights:

$$
\begin{aligned}
& \frac{\Delta^{T}-\Delta^{B}}{\phi}=\underbrace{(\hat{n}-\nu)\left(\omega^{B}-\omega^{A}\right)}_{\text {differential productivity effect }>0}+ \\
& \underbrace{\left[\omega^{B}\left(\hat{n}^{B}-\hat{n}\right)-\omega^{A}\left(\hat{n}^{A}-\hat{n}\right)\right]-\left[\omega^{B}\left(n^{B}-\nu\right)-\omega^{A}\left(n^{A}-\nu\right)\right]}_{\text {differential fertility effect }}+\underbrace{\frac{p}{\phi}\left(n^{A}-n^{B}\right)}_{\text {tradability effect }}
\end{aligned}
$$

Here, a third type of effect obtains referred to as the tradability effect and represented through the expression $p\left(n^{A}-n^{B}\right) / \phi$. Contrary to the two other effects, its sign is indeterminate. Depending on the price of the procreation entitlements, tradability will either be redistributive (when $p\left(n^{A}-n^{B}\right) / \phi>0$ ) or anti-distributive (when $p\left(n^{A}-\right.$ $\left.\left.n^{B}\right) / \phi<0\right)$. The following proposition specifies the conditions under which each case occurs.

\section{Proposition 4 (Redistributive Nature of Tradability)}

Define $\hat{p}(w) \equiv(\theta-\eta \phi w) / \eta$.

(i) If $\theta>0$, tradability is redistributive if and only if

$$
p<0 \text { or } p>\min \left\{\frac{\theta}{1-\phi \nu}, \hat{p}\left(\omega^{A}\right), \tilde{p}\left(\omega^{A}\right)\right\} \text {. }
$$

(ii) If $\theta=0$ tradability is always redistributive.

Proof: See Appendix D. 
Figure 2: Redistributive Nature of Tradability

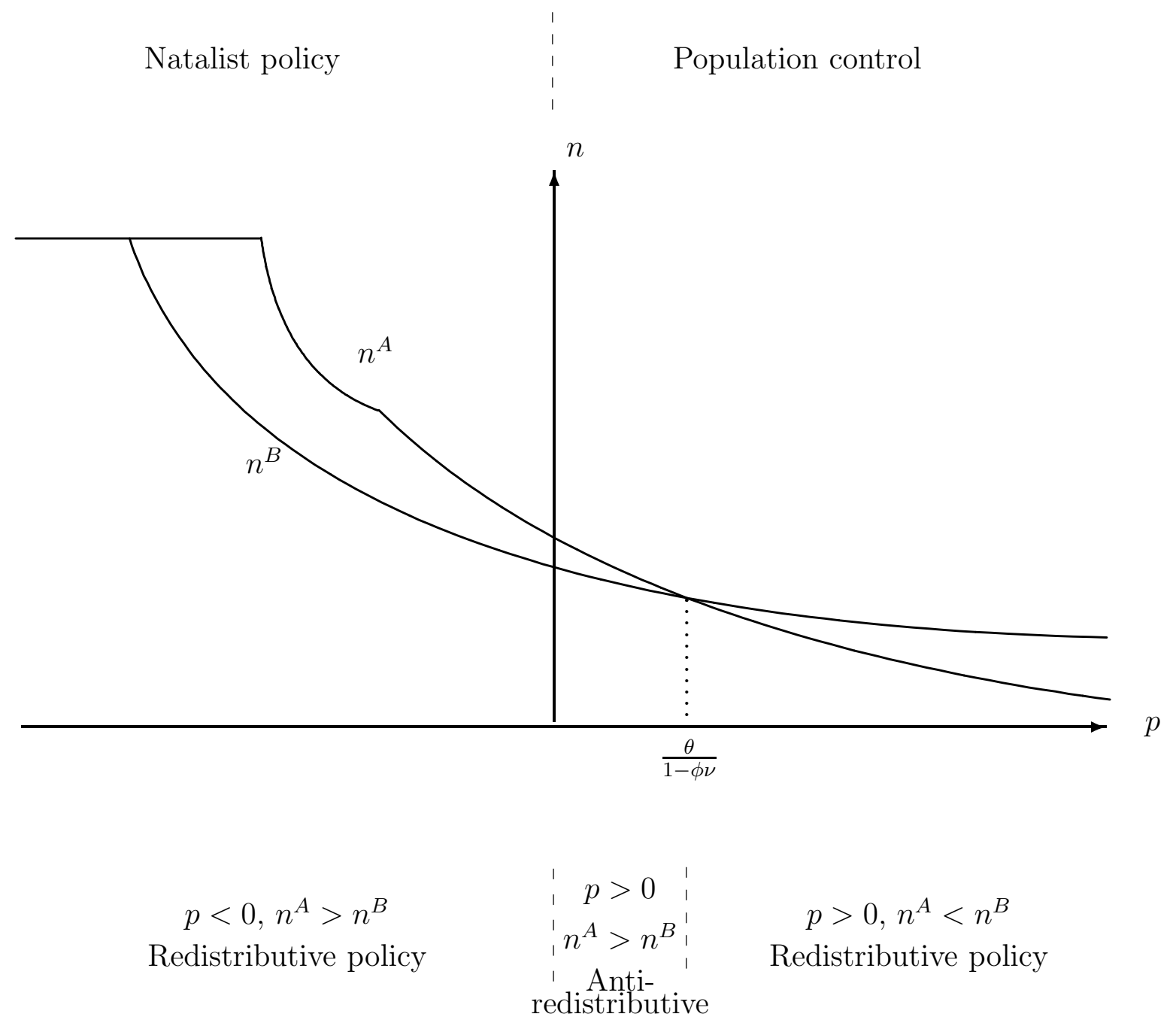


Figure 2 helps capturing the intuition underlying Proposition 4. When $p$ is negative, fertility is encouraged. Poor households have more children than the fertility target while the rich have less. Poor people sell the exemptions they receive to the rich which reduces the income gap between the rich and the poor. When $p$ is positive and large, having children is so expensive that rich people have more children than poor ones. This time, the poor end up below the target and the rich above. ${ }^{10}$ Yet this is also redistributive because poor people sell the procreation allowances they do not use to the rich (this is the case imagined by Boulding). It is only when the procreation price is modestly positive that tradability is anti-redistributive. ${ }^{11}$ In that case the price of allowances is not high enough to bring the poor under the target, and therefore to reverse the fertility differential. Poor households thus buy allowances from the rich and the income gap increases. Notice that if $\theta$ is close to zero, this possibility disappears.

One important issue is whether practical indications can be provided as to whether an actual scheme is likely to fall within the anti-redistributive zone identified in Figure 2. There is at least one consideration that is relevant here. If we focus on the distributive impact of tradability alone, if $\nu$ is lower but close to the existing fertility level, the price of the procreation allowances will not be large enough and we are likely to fall within the anti-redistributive zone. In other words, from the point of view of the tradability effect alone, the best guarantee for the scheme to have a distributive impact consists in adopting a radical reform, i.e. one involving a $\nu$ that diverges enough from the existing fertility rate. This is significant as gradual reforms in this field are more likely to be politically feasible than radical ones. Two conclusions can be drawn from this. First, if we take the tradability effect alone as illustrated in Figure 2, schemes implementing the proposed model are likely in practice to fall within the anti-redistributive zone, since radical changes are less politically feasible. Second, whether this would tend to make the scheme anti-redistributive all-things-considered does not necessarily follow as our discussion in Section 5 will illustrate.

\section{Effects on Education}

Let us now turn our attention to the effect of procreation entitlements on education. This is an important question because both social mobility and long-run income are positively

\footnotetext{
${ }^{10}$ At equilibrium the target is always equal to average fertility.

${ }^{11}$ This invites to look with a critical eye the widely shared view, also implied e.g. in Tobin (1970), that tradability promotes by nature inequality.
} 
affected by education spending. The following proposition shows how education depends on procreation price.

\section{Proposition 5 (Education and Procreation Price)}

Define

$$
\breve{p} \equiv \frac{-\theta}{\gamma \eta(1-\phi \nu)}<0 .
$$

Assume that the threshold $\dot{p}=\min \{\breve{p}, \tilde{p}(w)\}<-1 / \nu$. Investment in education $e$ is increasing in procreation price $p$.

Proof: From the expression for $e$ given in Proposition 6.

An increase in the procreation price reduces fertility (Proposition 2) and increases education, which is the usual quantity-quality tradeoff facing a rise in the cost of children. In this case, natalist policy would be bad for education, social mobility and long-run income, while population control would be good. ${ }^{12}$

One of the interesting effects of a pro-natalist policy is intergenerational and illustrates as well the interaction between the income and the educational impact of demographic policies. Let us consider two generations: $\mathrm{P}$ (parents) and C (children). And let us envisage a population target such that the procreation price is negative. Such a pro-natalist policy tends to reduce income inequalities within generation $\mathrm{P}$ due to the tradability effect. However, this raises a serious difficulty. For the very same pro-natalist policy, while reducing income inequalities within generation $\mathrm{P}$, will also reduce the average level of education (hence, the income level as well) of generation C. The pro-natalist subsidy is insufficient to compensate the income loss resulting from the fact that people with more children tend to work less. This entails that they will earn less and have less money to invest in education both in total and, a fortiori, per capita. In other words, a pro-natalist policy will end up leading to a situation such that, while being redistributive for generation $\mathrm{P}$, it will tend to increase income inequalities between generations $\mathrm{P}$ and $\mathrm{C}$. This is a problem e.g. because we may then end up with a world in which the worst off people are worse off than in the business-as-usual scenario (i.e. in the absence of pro-natalist policy). Does this constitute a sufficient reason to reject the proposed scheme altogether? We do not

\footnotetext{
${ }^{12} \mathrm{~A}$ special but practically marginal case arises when $p$ is extremely low and $\dot{p}>-1 / \nu$. In such a case, individual investment in education $e$ is decreasing in $p$ for $p<\dot{p}$ and increasing in $p$ for $p>\dot{p}$. Poor households are in regime R1; they are entirely specialized into the production of children $(n=1 / \phi)$. A small rise in $p$ has no effect on fertility, but has a negative income effect, which entails that education spending is reduced.
} 
think so. It rather stresses on the need to couple demographic policy with educational policy. We could then both get the redistributive impact at the generation $\mathrm{P}$ level without generating the negative impact on education (and income) for generation $\mathrm{C}$. In practice, this could take the form of education subsidies or publicly provided education.

\section{Moving from National to Global Level}

\section{Procreation Entitlements at the Global Level}

So far, we have assumed that tradable procreation permits were allocated at the domestic level. There may however be good reasons to look at the way in which the scheme could be applied to countries rather than to individuals. One such reasons is that those concerned with the scheme at the domestic level because of moral objections to its enforcement, may still be ready to accept that less coercive measures at the domestic level be combined with a scheme of tradable procreation permits among countries. Moreover, those willing on the contrary to promote the instrument domestically will generally be positively inclined towards simultaneously implementing it at the global level. Another reason to look more closely at a global version of the scheme is that one often cited mode of initial allocation, i.e. grandfathering, could possibly make sense at the global level while being far less plausible at the individual level.

Applied at the global level, the system would work along the same lines as a domestic one, involving two key moments. First, a global demographic target should be set for a given period. Second, we would need to decide about an initial allocation rule to distribute the quotas to each of the countries. Let us first consider a situation with a uniform distribution of entitlements, which is the case analyzed so far. Understanding agents in our model as countries or set of countries, all the results developed above can be applied at the global level. In particular, the market for procreation entitlements will clear at the equilibrium price, country specific fertility and education reacting as described by Propositions 2 and 5. The effect of tradability on income (gross national income here) will depend on the condition set in Proposition 4.

\section{Numerical Illustration}

To illustrate how our set-up would operate at the global level, a version of the model with a large number of agents (countries) will be solved numerically. In order to associate 
numerical values to our parameters $\eta, \phi ; \theta$, and $\gamma$, we first calibrate the benchmark case of Section 2 on a cross-section of countries. Next we simulate the introduction of procreation entitlements aiming at reducing the global fertility rate. Results could easily be generalized to the reverse situation of under-population.

\section{Calibration}

One period in the model lasts 25 years. The variables are measured with data from the World Development Indicators, averaging those available for the years 1998-2002. Variable $n$ is computed as the net reproduction rate, i.e. "Fertility rate, total (births per woman)" divided by two in order to obtain a fertility rate per person and multiplied by (1- "Mortality rate, infant (per 1,000 live births)" /1000) to measure net fertility per capita. Total education $\theta+e$ corresponds to the product of "Adjusted savings: education expenditure (\% of GNI)" and "GNI per capita, PPP (current international \$)" loading to a measure of education spending per capita in PPP dollars. Population size $N$ for each country is proportional to the population aged 15-64. Productivity per person $\omega$ is unobservable but can be obtained from Gross National Income $y$ as follows:

$$
y=\omega(1-\phi n / 25)
$$

We then estimate by Full Information Maximum Likelihood the parameters $\phi, \theta, \eta$ and $\gamma$ of the system (5)-(6)-(15):

$$
\begin{aligned}
& e_{i}=\left\{\begin{array}{ccc}
0 & \text { if } & \omega_{i} \leq \frac{\theta}{\eta \phi}+\varepsilon_{i}^{e} \\
\frac{\eta \phi \omega_{i}-\theta}{1-\eta} & \text { if } & \left.\omega_{i}>\frac{\theta}{\eta \phi}\right)
\end{array}\right. \\
& n_{i}=\left\{\begin{array}{ccc}
\frac{\gamma}{\phi(1+\gamma)} & \text { if } \quad \omega_{i} \leq \frac{\theta}{\eta \phi}+\varepsilon_{i}^{n} \\
\frac{(1-\eta) \gamma \omega_{i}}{\left(\phi \omega_{i}-\theta\right)(1+\gamma)} & \text { if } \quad \omega_{i}>\frac{\theta}{\eta \phi}
\end{array}\right. \\
& y_{i}=\omega_{i}\left(1-\phi n_{i} / 25\right)
\end{aligned}
$$

The estimation results are presented in Table 2. The point estimate for the parameter $\eta$, which measures the elasticity of income to schooling, is located well within the range of estimates of the elasticity of earnings with respect to schooling (see the discussion in de la Croix and Doepke (2003)). The estimated value for $\phi$ implies that one child takes 
Table 2: Estimation results

\begin{tabular}{lrrrr}
\hline \hline \multicolumn{4}{l}{ Number of observations $=158$} \\
\multicolumn{5}{l}{ Log likelihood $=-1210.94$} \\
\multicolumn{5}{c}{ Standard } \\
Parameter & Estimate & Error & t-statistic & P-value \\
$\eta$ & 0.578 & 0.0356 & 16.25 & {$[.000]$} \\
$\phi$ & 0.039 & 0.0057 & 6.798 & {$[.000]$} \\
$\theta$ & 43.18 & 4.9365 & 8.748 & {$[.000]$} \\
$\gamma$ & 0.107 & 0.0127 & 8.432 & {$[.000]$} \\
& & & & \\
Equation & education & fertility & & \\
R-squared & 0.88 & 0.50 & & \\
\hline \hline
\end{tabular}

$4 \%$ of available time during 25 years.

Relationships (16)-(17) are presented in Figure 3. The curves stand for two theoretical relationships: the productivity-fertility one (left panel), and the productivity-education one (right panel). Points correspond to countries. Notice that we provide an estimation of the productivity level below which no education takes place $e=0$. It is equal to $\theta /(\phi \eta)=1915$ dollars per person and per year. The curves fit well with R-squared of 0.88 and 0.50 respectively. This is especially so when we consider the small number of degrees of freedom allowed for by the model.

\section{Simulation}

Having estimated the parameters of the benchmark model, let us introduce procreation entitlements and compute how fertility and education react to the imposition of a fertility target in the various countries. The average fertility rate (per person) in the benchmark is equal to 1.38; we consider two cases, one with a target $\nu=1$ and another with $\nu=1.2$. We calculate the equilibrium procreation price by simulating the equilibrium defined in Definition 2. Prices $p_{t}$ ensuring that average fertility matches the target amount respectively to 55.87 for $\nu=1$ and to 21.44 for $\nu=1.2$. Figure 4 shows how procreation allowances modify fertility and education in each country. More specifically, we observe that in the case of a moderate population control policy $(\nu=1.2)$ fertility drops in poor countries, while the overall correlation between fertility and income remains broadly negative. The drop in fertility allows for a rise in education spending, especially for countries which were close to the threshold income. Education remains close to its former level 
Figure 3: Estimated relationships
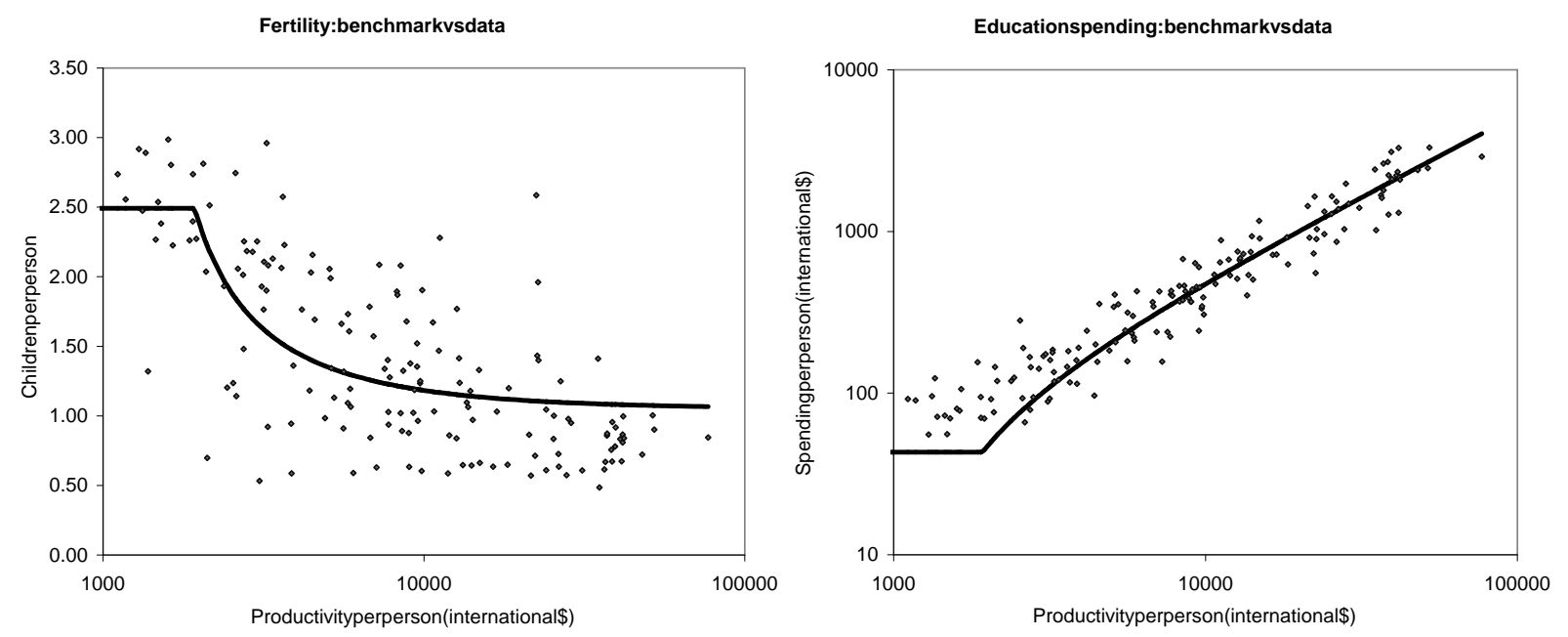

for both the very poor and the non-poor countries. With a stronger population control policy $(\nu=1)$, fertility drops proportionally more in poor countries. Moreover, the overall relation between fertility and income is now positively sloped. Education spending now increases for all the poor countries.

The redistributive effects of the two policies are displayed in Figure 5. For each country, we compute the difference in GDP per head between the simulation with population control and the benchmark. This comparison is directly in line with our analysis of income redistribution of the previous sections. We observe that all countries gain from population control policies. This is because the reduction in fertility cuts the cost of having children supported by the economy (here it consists only of the time-cost $\phi$ ) and all countries end with a higher income. We also observe in the Figure that poor countries gain more than rich countries, in particular in the simulation with a strong population control. Hence, the differential fertility effect outlined above dominates the other effects. Population control is thus redistributive.

To evaluate the gains from tradability, let us compare the equilibrium values of the procreation price to the threshold of Proposition $4 \theta /(1-\phi \nu)=44.93$. Recall that if $p_{t}$ is between 0 and this threshold, tradability is anti-redistributive. In the moderate policy scenario, $p_{t}=21.44<44.93$, and tradability is anti-redistributive. In contrast, under the strong policy scenario, $p_{t}=55.87>44.93$, tradability is redistributive. This application of the result of Proposition 4 is confirmed by the right panel of Figure 5 which displays 
Figure 4: Simulation results
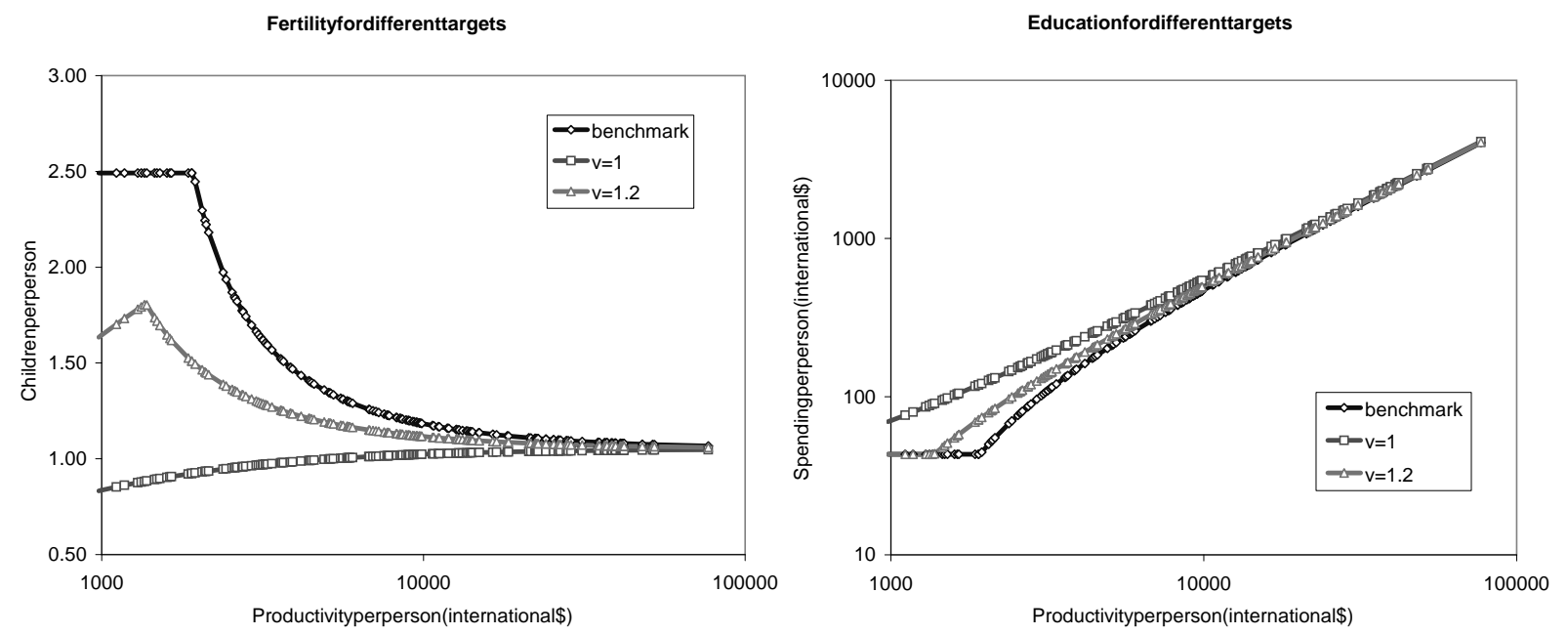

the part of total gains in GDP that traceable to the tradability effect.

\section{Procreation Rights with Grandfathering}

In the previous section, we asked ourselves whether a tradable procreation entitlements would necessarily have an anti-redistributive impact. The underlying intuition was that because of tradability, the wealthiest countries would be able to further increase the gap separating them from poorer countries. Our model demonstrates however that there is only one area in Figure 2 in which such anti-redistributive effects arise. Outside this zone, the scheme would rather have a redistributive impact. The key practical question was then be to identify where practical schemes envisaged in specific real-life circumstances would be located. The simulations of the previous section have shown that for a moderate population control policy, we may end in this anti-redistributive zone, while for stronger policies, it is more unlikely to be the case. In this section, we have a closer look at still another theoretical option that could have different distributive properties. Rather than implementing an equal per capita initial allocation of procreation quotas, we would do so on a grandfathering basis.

Grandfathering is a concept that originates from the late 19th century in the southern US states (see Rose (1906)). It consists in an attempt at further delaying the electoral enfranchisement of black people. As the franchise was formally broadened, extending to both white and black men, the introduction of poll tax and/or literacy requirements 
Figure 5: Income gains
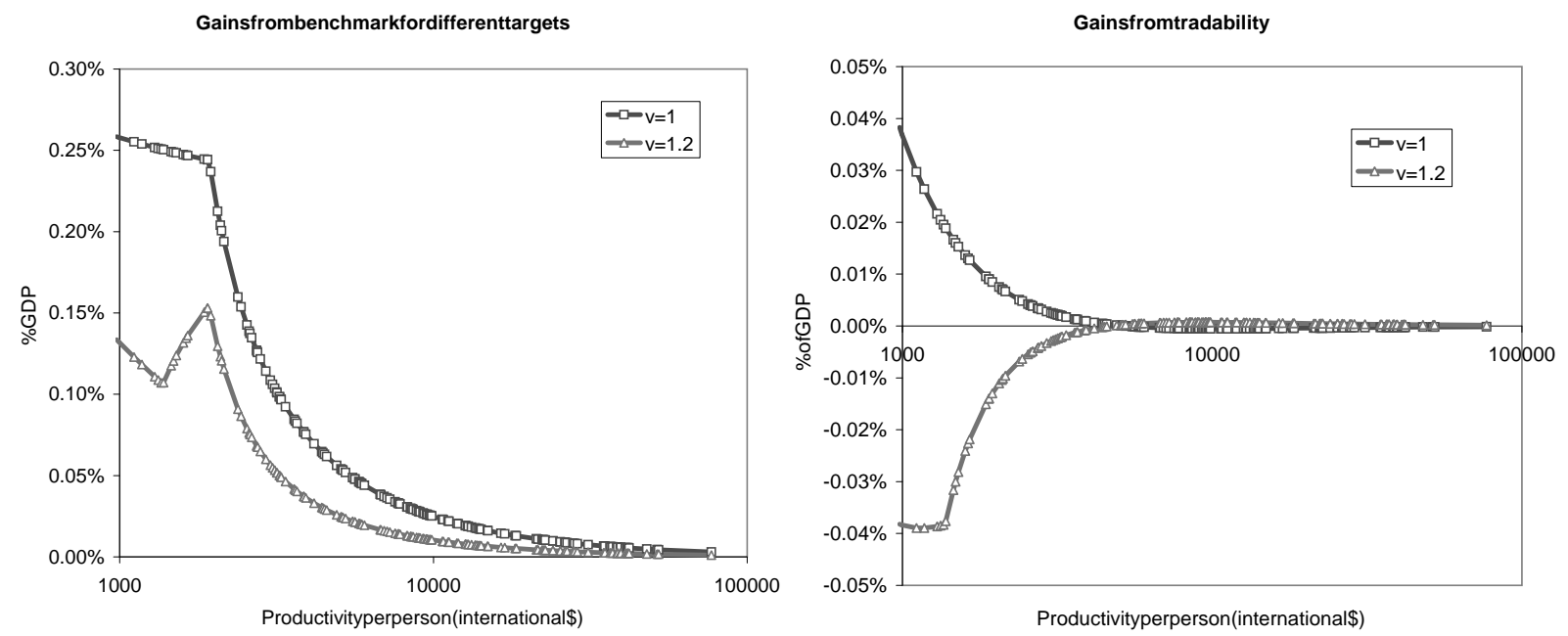

was supposed to slow down the access of most black people to the suffrage. It was also excluding some white men however, which arouse concern in the white community. This led to the introduction of the so-called "grandfather clause" in the electoral regime of some of the southern US states, stating that those whose grandfather or father was already enfranchised would be exempted from poll tax and/or literacy requirements. In practice, this meant that all white males would have the right to vote while still preserving the exclusion of most black males through poll tax and/or literacy requirements, from which they could not be exempted since none had had a grandfather entitled to vote.

By extension, the idea of grandfathering usually refers nowadays to the exemption from new regulation granted on a temporary basis to actors already involved in a given activity. More interestingly for us, it is used in the tradable emission permits context (such as the Kyoto context, see Bohringer and Lange (2005) and Gosseries (2005)) to refer to one mode of initial permits allocation, i.e. one that grants relatively larger shares of emission rights to those who already emit relatively more. This means that when facing a global emission reduction target, larger polluters will have to reduce their emissions in the same proportion as lesser polluters. This means that the larger polluters are partly exempted from the application of the new rule (relative exemption).

In the pollution reduction case, grandfathering can prima facie be expected to lead to anti-redistributive consequences when compared to an equal per capita allocation. For larger per capita polluters are also generally richer countries. In the procreation case, the 
relationship between fertility rate and wealth is not so straightforward and might actually be the reverse. This suggests that grandfathering in the case of tradable procreation entitlements could well have a distributive impact that differs both from the one exhibited in the case of grandfathering for tradable emission quotas and from the one unveiled in the previous section for tradable procreation entitlements allocated on a per capita basis. We now provide the analysis needed for the latter comparison.

We assume that countries receive an initial endowment of rights proportional to their fertility rate in the absence of procreation rights (benchmark): ${ }^{13}$

$$
\nu^{i}=\left.\mu n^{i}\right|_{p=0}
$$

Parameter $\mu$, when larger than one, indicates a pronatalist policy. Conversely, if $\mu$ is lower than one, population policy is restrictive. The previously defined average fertility target $\nu$ relates to the $\nu^{i}$ through:

$$
N^{A} \nu^{A}+N^{B} \nu^{B}=\left(N^{A}+N^{B}\right) \nu
$$

Since initial endowments are now different across countries, the income gap between countries becomes:

$$
\Delta^{G}=\omega^{B}-\omega^{A}+p\left(\nu^{B}-\tilde{n}^{B}\right)-p\left(\nu^{A}-\tilde{n}^{A}\right) .
$$

where fertility levels with a tilde denote fertility in the grandfathering case. Computing the difference in income gap between the benchmark case and the grandfathering one, we

\footnotetext{
${ }^{13}$ This is standardly done in practice for pollution rights. By referring to a base year preceding the conception of the scheme, we avoid the moral hazard problem consisting in trying to manipulate one's relative share before the entry into force of the system.
} 
obtain:

$$
\begin{aligned}
& \frac{\Delta^{G}-\Delta^{B}}{\phi}=\underbrace{(\hat{n}-\nu)\left(\omega^{B}-\omega^{A}\right)}_{\text {differential productivity effect }>0}+ \\
& \underbrace{\left[\omega^{B}\left(\hat{n}^{B}-\hat{n}\right)-\omega^{A}\left(\hat{n}^{A}-\hat{n}\right)\right]-\left[\omega^{B}\left(\tilde{n}^{B}-\nu\right)-\omega^{A}\left(\tilde{n}^{A}-\nu\right)\right]}_{\text {differential fertility effect }}+\underbrace{\underbrace{\frac{p}{\phi}\left(\tilde{n}^{A}-\tilde{n}^{B}\right)}_{\text {grandfathering effect }}}_{\begin{array}{l}
\text { tradability effect } \\
\frac{\phi \mu}{\phi}\left(\hat{n}^{A}-\hat{n}^{B}\right)
\end{array}}
\end{aligned}
$$

where the hatted variables represent fertility in case of grandfathering.

We can compare this expression with the one in equation (14). The differential productivity effect is unchanged. The differential fertility effect and the tradability effect have the same form as before, but $n^{A}$ and $n^{B}$ in (14) are now replace by $\tilde{n}^{A}$ and $\tilde{n}^{B}$ in (18). The two latter effects would play the same role as before provided that fertility behavior is only marginally altered by grandfathering. A fourth effect is the grandfathering effect. Since the poor country initially received more procreation rights per head than the rich one, an income transfer from the rich to the poor obtains in exchange for extra entitlements in case of positive procreation price. The direction of transfer is reversed in case of negative procreation price.

We still need to evaluate whether grandfathering modifies the fertility behavior in a quantitatively significant way. From numerical simulations carried on in our global model it appears that the difference in fertility levels between the model with equal allocation of rights and the one with grandfathering is very small, typically lower than three percentage points for any country. Investment in education also remains almost unchanged. Equilibrium procreation price are not much affected either, with $p_{t}=56.30$ instead of 55.87 for the radical policy $(\nu=1)$ and $p_{t}=21.66$ instead of 21.44 for the moderate policy $(\nu=1.2)$. The reason for these negligible effects on behaviors and equilibrium prices is that grandfathering acts as a lump-sum transfer (it is independent from effective bahavior) generating only a small income effect, without any direct distortion on the price of procreation.

We conclude from this that the essential difference between (18) and (14) is the last effect, which is a pure transfer. Grandfathering has a redistributive effect in the case of population control, simply by implementing a redistributive initial allocation of rights. While 
its effect on fertility distribution is small, simulations show the effect of grandfathering on income distribution can be large, increasing by $50 \%$ the gains in GDP for the poor countries compared to a system with a uniform allocation of rights.

\section{Conclusion}

In this paper, we explored the idea of tradable procreation entitlements, within a general equilibrium model with endogenous fertility. Both tradable allowances and tradable exemptions were envisaged, aimed at addressing problems of respectively over- and underpopulation. An equilibrium with such assets exists. It can thus implement any desired growth rate of population. Having shown this, we focus on worries as to the possible antiredistributive nature of such a scheme, as well as to possibly adverse impacts in terms of educational investments.

Three effects are identified and contrasted. While two of them also obtain in the case of fixed quotas schemes, a third one, the tradability effect, is specific to the present scheme. Insofar as income distribution is concerned, with procreation exemptions (whatever their price) or allowances if they are expensive enough, tradability redistributes resources from the rich to the poor. In contrast, cheap procreation allowances redistribute resources towards the rich. Since high prices are likely to obtain only if fertility target departs significantly from the benchmark demographic scenario and since radical reforms are politically more difficult to defend than moderate ones, the risk of an anti-distributive impact of the scheme is likely in case of initial allocation that would be equal per head.

As far as human capital is concerned, natalist policy would tend to reduce the average educational level of the next generation, while population control would increase it. In case of pro-natalist policies, sustaining education through additional measures may turn out to be helpful for future generations. Restricting ourselves to natalist policy, negative effects on the level of education should not necessarily be seen as reasons to reject the proposal altogether. Rather, it requires that the scheme itself be either modified accordingly (e.g. through changes in the initial allocation of permits) or complemented by other schemes aimed at countering such effects.

We next consider the global level by applying our model to countries, rather than to individuals, avoiding some of the enforcement difficulties involved in the domestic forms of such schemes. Feeding our model with real data from 158 countries we show how a 
global population control policy with tradable entitlements can reduce fertility in poor countries and enhance education. We also indicate to what extent an alternative allocation rule of procreation entitlements, granting rights in proportion to existing fertility levels (grandfathering) rather than on a per capita basis, can make population control even more redistributive.

Let us conclude by pointing at two interesting differences with tradable pollution quotas. First, population control is a two-sided problem, which requires the use of two types of entitlements, exemptions and allowances. Their joint operation guarantees that any target can be met. Second, while the rich tend to pollute more than the more, the poor tend to have more children than the rich. As a result, grandfathering is not always detrimental to the poor, as insights from environmental economics may suggest.

\section{References}

Becker, Gary S. 1960. "An Economic Analysis of Fertility." Demographic and Economic Change in Developed Countries. Princeton: Princeton University Press.

Bohringer, Christoph, and Andreas Lange. 2005. "On the design of optimal grandfathering schemes for emission allowances." European Economic Review 49 (8): 2041-2055 (November).

Boulding, Kenneth. 1964. The Meaning of the Twentieth Century. London: George Allen and Unwin Ltd.

Casella, Alexandra. 1999. "Tradable Deficit Permits. Efficient Implementation of the Stability Pact." Economic Policy 29:323-347.

Daly, Herman. 1991. Steady-State Economics. Second Edition. Washington DC: Island Press.

- 1993. "The Steady-State Economy: Toward a Political Economy of Biophysical Equilibrium and Moral Growth." In Valuing the Earth. Economics, Ecology, Ethics, edited by H Daly and KTownsend, 325-363. Cambridge/London: The MIT Press.

de la Croix, David, and Matthias Doepke. 2003. "Inequality and growth: Why differential fertility matters." American Economic Review 93 (4): 1091-1113.

Demeny, Paul. 1987. "Pronatalist policies in low-fertility countries: patterns, performance, and prospects." In Below-replacement fertility in industrial societies, edited 
by Kingsley Davis, Mikahail Bernstam, and Rita Ricardo-Campbell. Cambridge MA: Cambridge University Press.

Dworkin, Ronald. 2000. Sovereign Virtue. The Theory and Practise of Equality. Cambridge: Harvard University Press.

Golosov, Mikhail, Larry E. Jones, and Michele Tertilt. 2004, January. "Efficiency with Endogenous Population Growth." Nber working papers 10231, National Bureau of Economic Research, Inc.

Gosseries, Axel. 2005. "Cosmopolitan luck egalitarianism and climate change." Canadian Journal of Philosophy, p. forthcoming.

Greenhalgh, Susan. 2003. "Science, modernity, and the making of china's one-child policy." Population and Development Review 29 (2): 163-196.

Hathaway, James, and Alexander Neve. 1997. "Making International Refugee Law Relevant Again: A Proposal for a Collectivized and Solution-Oriented Protection." Harvard Human Rights Journal 10:115-211.

Heer, David. 1975. "Marketable Licences for Babies: Boulding's Proposal Revisited." Social Biology 22 (1): 1-16.

Joskow, Paul, Richard Schmalensee, and Elizabeth Bailey. 1998. "The market for sulfur dioxide emissions." American Economic Review 88 (4): 669-685.

Kremer, Michael, and Daniel L Chen. 2002. "Income Distribution Dynamics with Endogenous Fertility." Journal of Economic Growth 7 (3): 227-58 (September).

Lerner, Abba, and David Colander. 1980. MAP. A Market Anti-Inflation Plan. New York: Harcourt Brace Jovanovich.

Michel, Philippe, and Bertrand Wigniolle. 2006. "On Efficient Child Making." Economic Theory 27:1-20.

Rose, John. 1906. "Negro Suffrage: The Constitutional Point of View." American Political Science Review 1 (1): 17-643.

Schuck, Peter. 97. "Refugee Burden-Sharing: A Modest Proposal." Yale Journal of International Law 22 (2): 243-297.

Sen, Amartya. 1996. "Fertility and Coercion." University of Chicago Law Review 63 (3): 1035-1061. 
Tobin, James. 1970. "On limiting the domain of inequality." Journal of Law and Economics 13 (2): 263-277. 


\section{A Dynamics in the benchmark case}

Dynamics are described by:

$$
z_{t+1}=\frac{n^{A}\left(1-\pi^{A}\right) z_{t}+n^{B}\left(1-\pi^{B}\right)}{n^{A} \pi^{A} z_{t}+n^{B} \pi^{B}} \equiv f\left(z_{t}\right) .
$$

The function $f$ has the following properties:

$$
\begin{aligned}
f(0) & =\frac{1-\pi^{B}}{\pi^{B}}>0 \\
f^{\prime}(z) & =\frac{n^{A} n^{B}\left(\tau^{B}-\tau^{A}\right)}{\left(n^{A} \pi^{A} z+n^{B} \pi^{B}\right)^{2}}>0 \\
f^{\prime \prime}(z) & =\frac{2\left(n^{A}\right)^{2} \pi^{A} n^{B}\left(\tau^{A}-\tau^{B}\right)}{\left(n^{A} \pi^{A} z+n^{B} \pi^{B}\right)^{3}}<0
\end{aligned}
$$

The dynamics of $z_{t}$ admit a single positive steady state:

$$
z=\frac{n^{A}\left(1-\pi^{A}\right)-n^{B} \pi^{B} \sqrt{\left(n^{B} \pi^{B}-n^{A}\left(1-\pi^{A}\right)\right)^{2}+4 n^{A} \pi^{A} n^{B}\left(1-\pi^{B}\right)}}{2 n^{A} \pi^{A}},
$$

which is globally stable thanks to the properties of $f($.$) .$

Long-run income per capita is given by

$$
\frac{Y}{N^{A}+N^{B}}=\frac{\omega^{A} N^{A}\left(1-\phi n^{A}\right)+\omega^{B} N^{B}\left(1-\phi n^{B}\right)}{N^{A}+N^{B}}=\frac{\omega^{A} z\left(1-\phi n^{A}\right)+\omega^{B}\left(1-\phi n^{B}\right)}{z+1},
$$

and is a negative function of long-run $z$.

\section{B Solution to the Household Maximization Problem}

We study the following Kuhn-Tucker problem:

$$
\max _{c, e, n}\{\ln [c]+\gamma \ln [n]+\gamma \eta \ln [\theta+e] ; w(1-\phi n)-n e+p(\nu-n) \geq c \geq 0,1 / \phi \geq n, e \geq 0\}
$$

It is obvious from the properties of the utility function (non satiety and $u^{\prime}(0)=+\infty$ ) that optimal consumption is positive and that the budget constraint holds with equality; we can thus substituting $c$ from the budget constraint into the utility function. The problem 
becomes:

$$
\max _{e, n}\{\ln [w(1-\phi n)-n e+p(\nu-n)]+\gamma \ln [n]+\gamma \eta \ln [\theta+e] ; 1 / \phi \geq n, e \geq 0\}
$$

The Kuhn-Tucker conditions are:

$$
\begin{aligned}
a+\frac{\gamma \eta}{e+\theta}-\frac{n}{-(e n)+w(1-n \phi)+p(-n+\nu)} & =0 \\
-b+\frac{\gamma}{n}+\frac{-e-p-w \phi}{-(e n)+w(1-n \phi)+p(-n+\nu)} & =0 \\
a e & =0 \\
b\left(-n+\frac{1}{\phi}\right) & =0 \\
a & \geq 0 \\
b & \geq 0 \\
n & \leq \frac{1}{\phi} \\
e & \geq 0
\end{aligned}
$$

The first-four equations define a system that we can solve for $(a, b, n, e)$. There are four solutions:

$$
\begin{gathered}
b=\frac{\phi((1+\gamma) \theta-w(1+\gamma \eta) \phi-p(1+\gamma-\gamma(1-\eta) \nu \phi))}{\theta-p(1-\nu \phi)}, a=0, \\
e=\frac{-\theta-p \gamma \eta(1-\nu \phi)}{1+\gamma \eta}, n=\frac{1}{\phi} \\
b=\frac{\phi(w \phi+p(1+\gamma(1-\nu \phi)))}{p(1-\nu \phi)}, a=-\frac{\gamma \eta}{\theta}-\frac{1}{p(1-\nu \phi)}, e=0, n=\frac{1}{\phi} \\
b=0, a=\gamma\left(\frac{1}{p+w \phi}-\frac{\eta}{\theta}\right), e=0, n=\frac{\gamma(w+p \nu)}{(1+\gamma)(p+w \phi)} \\
b=0, a=0, e=\frac{\eta(p+w \phi)-\theta}{1-\eta}, n=\frac{\gamma(1-\eta)(w+p \nu)}{(1+\gamma)(p-\theta+w \phi)}
\end{gathered}
$$

From these equations we can fully characterize the solution to the individual problem.

Proposition 6 (Solution to the Individual Problem) Define the following thresh- 
old values for the procreation price:

$$
\begin{aligned}
\hat{p}(w) & \equiv \frac{\theta-\eta \phi w}{\eta} \\
\tilde{p}(w) & \equiv \frac{\theta(1+\gamma)-(1+\eta \gamma) \phi w}{\gamma(1-(1-\eta) \phi \nu)+1} \\
\bar{p}(w) & \equiv \frac{-\phi w}{\gamma(1-\phi \nu)+1}<0 \\
\breve{p} \quad & \equiv \frac{-\theta}{\gamma \eta(1-\phi \nu)}<0
\end{aligned}
$$

Assume that (C1) and (C2) hold.

$R 1$ If $p<\breve{p}$ and $p<\tilde{p}(w), n=1 / \phi$, and

$$
e=\frac{-\gamma \eta(1+\phi \nu) p-\theta}{1+\gamma \eta}>0 .
$$

R2 If $p>\breve{p}$ and $p<\bar{p}(w), e=0$ and $n=1 / \phi$.

R3 If $p<\hat{p}(w)$ and $p>\bar{p}(w), e=0$ and

$$
n=\frac{\gamma(w+\nu p)}{(\phi w+p)(1+\gamma)}<\frac{1}{\phi}
$$

$R_{4}$ If $p>\hat{p}(w)$ and $p>\tilde{p}(w)$,

$$
\begin{aligned}
& e=\frac{\eta \phi w-\theta+\eta p}{1-\eta}>0, \quad \text { and: } \\
& n=\frac{(1-\eta) \gamma(w+\nu p)}{(\phi w-\theta+p)(1+\gamma)}<\frac{1}{\phi} .
\end{aligned}
$$

The function $\hat{p}(w)$ is obtained by solving for $p$ the condition $e=0$ in Equation (22) or the condition $a=0$ in Equation (21). The function $\tilde{p}(w)$ is obtained by solving for $p$ the condition $n=1 / \phi$ in Equation (22) or the condition $b=0$ in Equation (19). The function $\bar{p}(w)$ is obtained by solving for $p$ the condition $b=0$ in Equation (20) or the condition $n=1 / \phi$ in Equation (21). The threshold $\breve{p}$ is obtained by solving for $p$ the condition $a=0$ in Equation (20) or the condition $e=0$ in Equation (19).

The threshold procreation prices defined in Proposition 6 display two interesting proper- 
ties. First, we can unambiguously rank them when the wage is equal to zero:

$$
\hat{p}(0)>\tilde{p}(0)>\bar{p}(0)=0>\breve{p} .
$$

Second, they all intersect at the same point:

$$
\text { at } w^{\star}=\frac{\theta(1+\gamma(1-\phi \nu))}{\gamma \eta \phi(1-\phi \nu)}, \quad \hat{p}\left(w^{\star}\right)=\tilde{p}\left(w^{\star}\right)=\bar{p}\left(w^{\star}\right)=\breve{p}
$$

We represent these four lines and the corresponding regimes R1 to R4 in Figure 6. Let us now consider a household with wage $w$. Starting from a very high price $p$, the solution will be in regime R4. Letting the price drop, and abstracting from the constraint $(\mathrm{C} 2)$, two situations can arise. If $w<w^{\star}$, the succession of regimes will follow $\mathrm{R} 4 \rightarrow \mathrm{R} 3 \rightarrow \mathrm{R} 2$ $\rightarrow \mathrm{R} 1$ as prices drop; if $w \geq w^{\star}$, we will pass from $\mathrm{R} 4$ to $\mathrm{R} 1$ directly. When we take into account the constraint $(\mathrm{C} 2)$, regime $\mathrm{R} 1$ will never be a possible outcome for households with a very high wage.

All claims in Corollary1 are a direct consequence of the results of Proposition 6. From Equation (30), $\partial n / \partial w=-\gamma(1-\eta)(\theta-p(1-\phi \nu)) /\left[(1+\gamma)(p-\theta+\phi w)^{2}\right]$.

Proposition 2: From the expression for $n$ given in Proposition 6 we find that

$$
\mathrm{R} 1 \& \mathrm{R} 2: \frac{\partial n}{\partial p}=0, \quad \mathrm{R} 3 \& \mathrm{R} 4: \frac{\partial n}{\partial p}<0
$$

\section{Proof of Proposition 3}

If $\tilde{p}\left(\omega^{B}\right)>-1 / \nu$, both fertility levels tend to $1 / \phi$ when $p$ approaches $-1 / \nu$. Hence, for $p$ going from $-1 / \nu$ to $+\infty$, total fertility $\left(N^{A} n^{A}+N^{B} n^{B}\right) /\left(N^{A}+N^{B}\right)$ goes monotonically from $1 / \phi$ to zero. A each date, there exist therefore a price $p_{t}$ for which

$$
\left.\left(N_{t}^{A} n_{t}^{A}+N_{t}^{B} n_{t}^{B}\right) /\left(N_{t}^{A}+N_{t}^{B}\right)=\nu \in\right] 0,1 / \phi[
$$

which is the equilibrium price satisfying equation (11). This price is unique because fertility is a monotonous function of $p$. 
Figure 6: Solution to the individuals problem: regimes R1 to R4

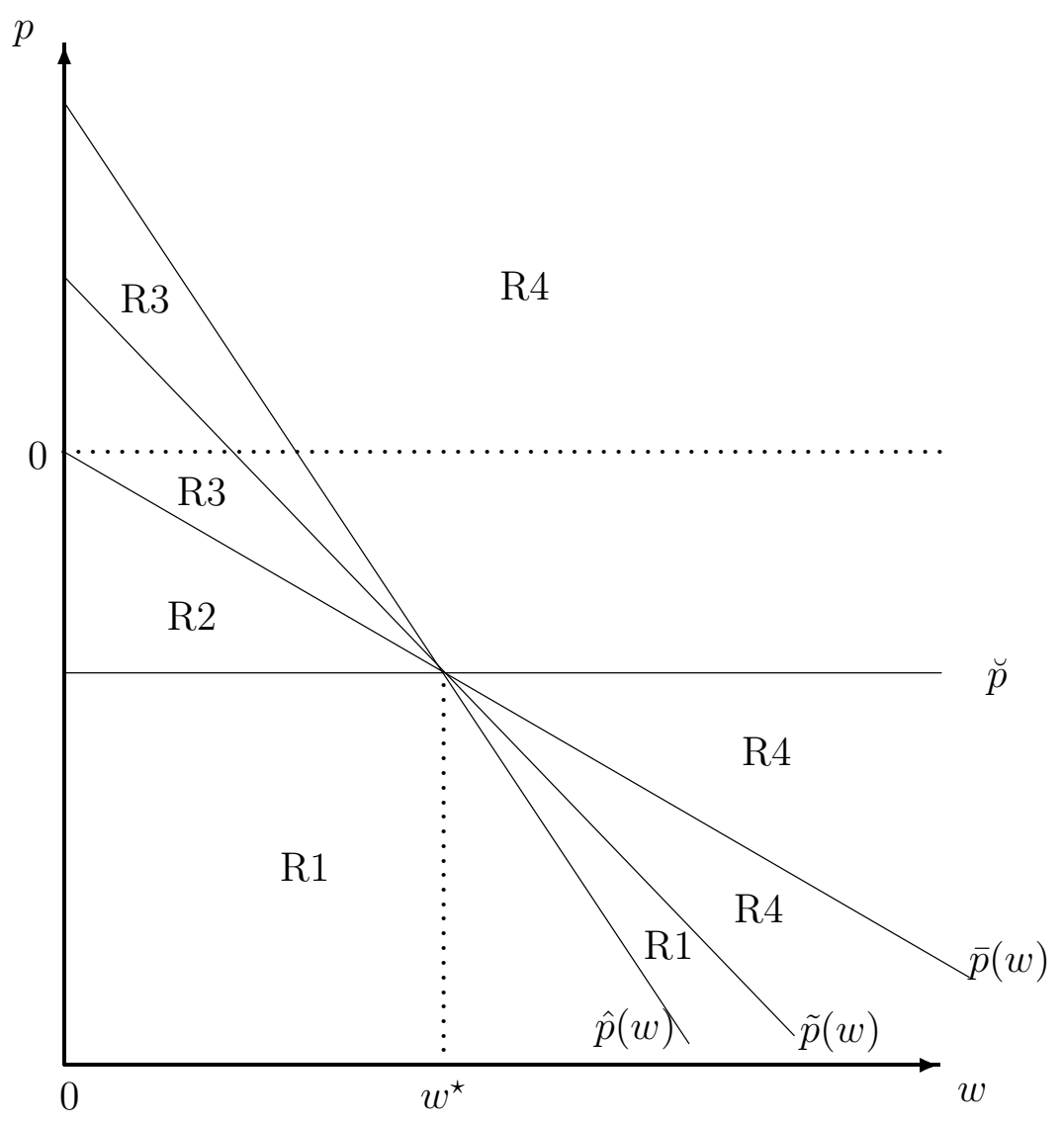

\section{Proof of Proposition 4}

The tradability effect is given by:

$$
M=\frac{p}{\phi}\left(n^{A}-n^{B}\right)
$$

(i) To analyze the sign of $M$, we should consider the different possible regimes. From Figure 6, if the poor is in R1, the rich can be either in R1 or in R4. If the poor is in R2, the rich can be in $\mathrm{R} 2, \mathrm{R} 3$ or in $\mathrm{R} 4$. If the poor is in $\mathrm{R} 3$, the rich can be in $\mathrm{R} 3$ or $\mathrm{R} 4$. If the poor is in the interior regime $\mathrm{R} 4$, the rich is in $\mathrm{R} 4$ too. We thus have eight situations to consider.

Cases were both types of households are either in R1 or in R2 are excluded by assumption 
(C1). Indeed, in that case, aggregate fertility per person would be $1 / \phi$ and the equilibrium condition (11) would be violated. This leaves us with six different cases.

When the poor is in $\mathrm{R} 2$, the procreation price is necessarily negative, and $n^{A}=1 / \phi>n^{B}$. When both individuals are in R3, the procreation price can be either positive or negative, but we always have $n^{A}>n^{B}$ because fertility decreases in income in regime R3. Hence, $p<0 \rightarrow M<0$ in this regime. When the poor is in R3 and the rich in R4, we also always have $n^{A}>n^{B}$ (compare (28) to (30)), which implies in this regime $p<0 \leftrightarrow M<0$. Finally, if both individuals are in the interior regime R4, we can use Proposition 1 to infer that if $p<0\left(n^{A}>n^{B}\right)$ or if $p>\frac{\theta}{1-\phi \nu}\left(n^{B}>n^{A}\right)$, then $M<0$. The min term in the condition of the proposition gathers the requirement of being in regime R4 with the condition of Proposition 1.

(ii) If $\theta=0$ the expression

$$
\min \left\{\frac{\theta}{1-\phi \nu}, \hat{p}\left(\omega^{A}\right), \tilde{p}\left(\omega^{A}\right)\right\}
$$

is negative and the condition in (i) is always true. 
Département des Sciences Économiques de l'Université catholique de Louvain

Institut de Recherches Économiques et Sociales

Place Montesquieu, 3

1348 Louvain-la-Neuve, Belgique 